\title{
Examining A Decade Of Reading And Mathematics Student Achievement Among Primary And Secondary Traditional Public School And Charter School Students: A Meta-Analytic Investigation
}

\author{
Matthew J. Erickson, Slippery Rock University of Pennsylvania, USA \\ Karen H. Larwin, Youngstown State University, USA \\ Robert S. Isherwood, Slippery Rock University of Pennsylvania, USA
}

\begin{abstract}
The current investigation will synthesize numerous studies conducted across the nation at the elementary, middle and high school levels. Meta-analytic techniques will assist parents and educators in making evidence-based decisions while adding to the research supporting educational reform and promoting best practices in both educational models. This study was specifically designed to consider a number of variables in charter schools relative to traditional public schools, including socioeconomic status, English language learning, school competition, and eligibility for special education that may impact student mathematics and reading achievement. The findings of the current investigation suggest that students in charter school programs are not performing as well as students in traditional public schools on mathematics and reading achievement examinations.
\end{abstract}

Keywords: Charter Schools; School Choice; Meta-Analysis; Mathematics Achievement; Reading Achievement

\section{INTRODUCTION}

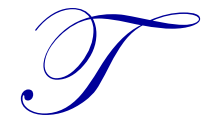

he charter school concept was created by University of Massachusetts Professor Ray Budde in 1974. He shared his ideas in a publication titled Education by Charter. "Budde used the term 'charter' because he had been urging school districts to do what European kings had done for explorers--give them a 'charter' to explore" (Vergari, 2002, p. 20). This new charter idea would provide the opportunity for educators to use new approaches to teach math, reading and other academic subjects (Vergari, 2002). Following the publication of A Nation at Risk, Budde's (1974) publication caught the attention and support of Al Shanker, President of the American Federation of Teachers (uscharterschools.org, 2009). The troubling data in the 1980s showed that schools were in danger and changes were needed. The idea that charters would be developed on the values of opportunity, choice, and responsibility for results began to gain attention (uscharterschools, 2010).

\section{Charter Schools Providing Choice and Opportunity to Students and Society}

Charter schools may provide an array of curricular options for students. The ability for a charter school to specifically focus on business, science, mathematics, technology, engineering, performing arts, dual language, culture, leadership, or a traditional school model may draw the attention of students interested in pursuing a career in the field that a charter school may provide as a specialized opportunity. "Charter schools are schools of choice; choice to parents, students, teachers, and administrators" (Chen, 2007). According to Greene, Forster, and Winters (2003), special-focus or alternative schools tend to target students with educational disadvantages, students at those 
schools typically do more poorly in school and perform worse on assessments than their traditional education peers. According to the Office of Program Policy Analysis \& Government Accountability (2005), the average charter school student is academically behind when entering charter schools compared to students remaining in traditional public schools. For this reason, charter school students are less likely to meet grade-level standards compared to students in traditional public schools; however, students who are furthest behind make slightly more progress in charter schools than do students in traditional public schools.

\section{An Era of Accountability}

Through the evolution of educational policy from the pauper schools, common schools crusade, and normative dominance through the standards movement of the 1990s to today's focus on accountability, one can argue that charter schools are still a new concept in relation to other educational eras and cannot yet be considered effective or ineffective (Gronberg \& Jansen, 2001; Tyack \& Cuban, 1995). The tremendous growth of charter schools forced competition among school entities in hopes that each educational setting would reap the benefits (Barr, 2007; Booker, Gill, Zimmer, \& Sass, 2007; Greene, Forster, \& Winters, 2003; Gronberg \& Jansen, 2001).

Questions about the effectiveness of individual schools were not a pressing matter in public education because the schools were assumed to be permanent and had never faced competition (Tyack \& Cuban, 1995; Hill, Angel, \& Christensen, 2006). School effectiveness became a major research issue only when states and localities considered accountability schemes that could lead to school closure and replacement. Now there is a sense of urgency about how to judge individual schools, due both to the rise in the number of charter schools and the implementation of No Child Left Behind" (Hill et al., 2006, p. 144).

\section{Competition}

Economist Milton Friedman once stated that "competition is a way in which both public and private schools can be required to satisfy their customers" (Thurman, 2010). "Montgomery (2004) noted that "charter schools implement innovative classrooms, longer school days, urban boarding schools and experiential education programs that are paying off through the enhancement of academic growth and parent satisfaction' (p. 1). Charter school advocates claim that charter schools will not only provide greater gains in student achievement to students who enroll, but will also foster competition that will lead to increases in the quality of traditional public schools (Booker, Gill, Zimmer, \& Sass, 2007).

Booker, Gilpatric, Gronberg, and Jensen (2005) investigated the effects of charters on traditional public schools by looking for changes in student achievement outcomes in traditional public schools following charter market penetration. Using an 8-year panel of data on individual test scores for public school students in Texas, research indicates a positive and significant effect of charter school penetration on traditional public school outcomes supporting the potential for systemic achievement gains from completion-enhancing school reform policies (p. 3-4). Positive effects consistent across both mathematics and reading scores support claims that expanding school choice may generate systemic gains (p. 21).

\section{School Choice}

Charter schools spring from the impulse to meet educational needs that are not being fulfilled in the home school district. They respond to frustrations, demands, and dreams that the regular system - for whatever reason-is not satisfying (Smith, 2001, p. 20). The largest discrepancy between the intended and actual outcomes of charter school legislation must focus on the many different directions taken by the initial legislation passed in Minnesota (Noblit \& Dickson, 2001; Vegari, 2002). With each state having the autonomy of creating its own charter school legislation, different procedures and protocols provide a level of variability across the country (Noblit \& Dickson, 2001; Vegari, 2002).

$\mathrm{Ni}$ and Arsen (2011) conducted a study to determine which public school districts felt the most pressure from school choice initiatives. Their study focused on the students who choose to stay in traditional public schools as opposed to students enrolled in charter schools. The purpose was to identify if traditional public schools provided 
better educational opportunities due to competition. $\mathrm{Ni}$ and Arsen found that the desire for school choice is more often expressed in urban areas than in other demographic areas. According to the National Charter School Resource Center (n.d.), charter schools are leading innovation in cities across the country and increasing access to high-quality educational options in urban neighborhoods. To build on the strength of the charter movement, several urban communities are embracing charter schools as an integral component of citywide reform initiatives that are designed to improve the quality of public education for all students.

Central city and low-income suburban districts have experienced the greatest decline of enrollment in traditional public schools due to school choice competition (Ni \& Arsen, 2011; Lacireno-Paquet, Holyoke, Moser, \& Henig, 2002). Results show that Detroit City Schools have lost approximately a third of their students to charter schools (Ni \& Arsen, 2011). Data indicates that rural districts in Michigan have the lowest average of participation in charter schools due to lack of availability of charter programs in rural areas. Ni and Arsen (2011) concluded that school choice activity is significantly influenced by socioeconomic characteristics of students.

\section{Student Achievement}

"Improving student learning is among the most important goals of charter school programs, and scholars and policy makers alike have been awaiting evaluations of how charter schools have affected student achievement" (Bifulco \& Ladd, 2004, p. 4). Bifulco and Ladd (2004) described several ways in which charter schools might improve student achievement (p. 5). First, they may increase the performance of the students who choose them by providing more effective learning environments than traditional public schools. Charter schools might do this by hiring more effective teachers, by using resources more efficiently, or by attracting a more motivated set of students who provide positive spillover benefits to other students. Second, even if charter schools are no more effective than traditional public schools for the typical student, they might benefit some students by providing alternative educational environments and programs. Students considered at risk in traditional school settings, for example, might do better in charter schools if those schools offer smaller, more intimate educational environments, specialized curricula, or targeted support services. Finally, the achievement of students in traditional public schools could rise if the competition from charter schools for students and funding enticed traditional public schools to become more productive.

Chau, McCaffrey, Zimmer, Daley, and Gill (2003) stated that charter school advocates have often touted charters as a means to give choices to disadvantaged students who otherwise lack choice (Nathan, 1998). Researchers found that students who attend charter schools were average or lower performing than other students at the traditional public school that they leave; the performance gap is greatest for Black students (National Charter School Research Project, 2005).

\section{Prior Charter and Traditional Public School Studies}

The majority of current research focusing on academic achievement in traditional public and charter schools focuses on mathematics and reading scores from state assessments. Results of the current research on charter school achievement tend to produce mixed results regardless of the methods used, with some providing positive results, some negative, with null or mixed findings the most common. Studies that find mixed results may attribute differences to their methodological approach. A number of charter school studies found mixed results for mathematics and reading student achievement when compared to traditional public schools (Barr, 2007; Booker et al., 2007; Tang \& Betts, 2006; Witte, Weimer, Shober, \& Schlomer, 2007; Zimmer et al., 2003; Zimmer et al., 2009; Zoblotsky, Qian, Ross, \& McDonald, 2008).

\section{Charter Schools Outperforming Traditional Public Schools}

A number of studies found positive effects for charter schools that are consistent across various assumptions concerning comparison groups, subjects, and grades demonstrating growth in achievement at a pace that often exceeds expected growth according to state and national norms (Ball State University, 2004; Comey, 2008; Florida Department of Education, 2009; Hoxby, 2004; McDonald, Ross, \& Bol, 2007; Miron, Cullen, BrooksApplegate, \& Farrell, 2007; Rattermann, \& Reid, 2009; Witte et al., 2004; Woodworth, David, Guha, Wang, \& Lopez-Torkos, 2008). 


\section{Traditional Public Schools Outperforming Charter School Achievement Scores}

Studies conducted for students in Michigan including Eberts \& Hollenbeck (2001) found that Michigan charter schools scored three to seven percent lower than comparable host districts on state criterion reference examinations. Horn and Miron's (2000) earlier study was slightly less negative, finding that charter school trends were either indistinguishable from or lower than those of their host districts in all grades and areas except fifth grade science" (Miron \& Nelson, 2001, p. 18). Bilfulco and Ladd's 2006 study of the impacts of charter schools on student achievement in North Carolina "utilized a fixed-effects model and found that students make considerably smaller achievement gains in charter schools than they would have if they stayed enrolled in public schools; however, this negative effect diminishes as charter schools gain more operating experiences (p. 7)".

\section{No Significant Difference}

A comparative study conducted by Miller (2003) focusing on elementary-level students in Idaho traditional public schools and charter schools found no significant difference between mathematics and reading achievement among students. Miller claimed that while there are demographic differences between charter schools and their constituent school districts, there is essentially no difference in student achievement when the charters are compared to the most closely watched elementary school in the constituent district (Akey et al., 2008). Barr, Sadovnik, and Visconti (2006) concluded that charter schools are similar to district urban public schools, with pockets of excellence and mediocrity.

\section{PURPOSE}

The current investigation seeks to resolve the contradictions that are present regarding the impact of charter schools in the existing research. This study is the first known study that synthesizes the existing research on the impact of charter schools versus traditional public schools on student achievement results across the last decade of No Child Left Behind (Buddin \& Zimmer, 2005).

\section{METHODS}

Glass (1976) maintained that the purpose of meta-analysis is to summarize and describe the results of studies in the existing research literature. The goal of meta-analysis is to estimate true effects or relationships. Prior to meta-analytic studies, research literatures were conflicting and contradictory as the number of studies on a particular question grew, causing feelings of frustration and intolerability (Hunter \& Schmidt, 1990). Hunter and Schmidt (1990) stated that meta-analytic studies present much less conflict between studies than had been believed when combining a number of studies to find an effect; coherent, useful, and generalizable conclusions can be drawn from research literatures.

To conduct a meta-analysis on student achievement in traditional and charter public schools, we first conducted an exhaustive search of the existing quantitative literature. Using a number of appropriate parameters focusing on key words, publication dates, and assessments used, a number of studies fit the provided criteria that contained the data needed for analysis. According to Glass et al. (1981), the next step to a meta-analysis is to describe, classify and code all the research studies to be included in the meta-analysis. To ensure measurement consistency, Glass et al. recommended that studies be coded a minimum of two times to establish rater agreement. Moderator variables must be clearly defined so raters are able to make clear distinctions between classifications.

\section{Current Investigation's Research Questions}

The present meta-analysis seeks to examine the following questions: What is the impact of charter versus public school on student achievement across the areas of mathematics and reading; across different student levels (i.e., elementary, middle, high school); across the different types of achievement measures (district, state, regional, for-profit); across different geographic regions; across different socioeconomic statuses; across different populations (urban, suburban, rural); across schools indicating the pressure or absence of English language learners (ELL); across schools indicating the presence or absence of special education; across schools with or without lottery 
systems; across different data sources (dissertation, professional organization, college or university); and across the publication years of the studies included in the analysis?

Studies included in this meta-analysis were collected through exhaustive electronic searches. Data bases including Digital Dissertations, Educational Resources Information Center (ERIC), EBSCO, Electronic Journal Center (EJC), Google Scholar, and JSTOR were utilized. This search examined research spanning from 2001 to 2012. The descriptive search criteria that were employed to identify relevant materials included such combinations as charter school achievement, charter schools student achievement, public school student achievement, academic achievement in charter and public schools, as well as each of these criteria with the addition of elementary, middle, and high school students. Abstracts of articles were reviewed and evaluated. Articles that did not meet the initial inclusion criteria were removed. The inclusion criteria included (a) articles examining student or academic achievement in traditional public and charter schools, (b) articles examining the instruction of students in K-12 schools, and (c) articles examining the use of an achievement assessment. Studies that were published prior to 2001 were excluded from the study; however studies that include achievement data prior to 2001 are included. Studies specifically focusing on online learning, distance learning, cyber schools or cyber charter schools were excluded due to the limited research conducted.

\section{Interpretation of Effect Sizes}

Cohen's (1992) suggested guidelines for interpreting effect size measures indicated that a large effect size is one that is greater than 0.5 ; a medium effect size is at least 0.3 ; and a small effect size is less than 0.1 . Cohen (1988) stated that "there is a certain risk inherent in offering conventional operational definitions for those terms for use in power analysis in as diverse a field of inquiry as behavioral science" (p. 25). If a standard had not been established within a respective field of study, Cohen suggested that this guideline be applied.

\section{RESULTS}

The initial search for studies relating to key words and phrases including charter school achievement, charter schools student achievement, public school student achievement, and academic achievement in charter and public schools revealed a total of 76 studies. After eliminating studies that did not focus on school-age students from kindergarten through 12th grade using an academic achievement test that was published after 2001, 47 studies met the selection criteria. After setting the selection criteria to perform an analysis that specifically provided comparison data on reading and mathematics student achievement in traditional public schools relative to charter schools, 13 studies met the criteria for analysis. Two studies representing five effect sizes were removed from the analysis due to extremely large sample sizes compared to all others (i.e., Booker et al., 2007; Zimmer et al., 2003). These two studies have sample sizes in excess of $n=1.8$ million students. After eliminating these two studies, a total of 11 studies were included in the final analysis. These 11 studies provided a total of 122 effect-size measures.

The 12 primary and secondary questions were used to identify the 11 moderators that were coded and analyzed using (CMA) to determine if there were any significant effects of the characteristics of traditional public schools and charter schools on student achievement and if so, what were the levels of the effects across the various levels of the moderators.

\section{Descriptive Analysis of Effect Sizes}

The primary purpose of this meta-analytic investigation was to investigate the impact of charter versus public education on student achievement across a number of moderators. A comprehensive review of the literature produced 11 studies that met the inclusion criteria, including 6 studies from professional organizations, 2 dissertations, and 3 studies completed by universities. The effect size measures within the study ranged from -8.650 to 2.140, yielding a grand mean overall effect size measure $d=-.270, p<.001$, a significant negative, small- to moderate-sized effect according to Cohen's (1992) guidelines for effect sizes. This result indicates that charter school educational programs are producing lower achievement scores in reading and mathematics, when compared to traditional public schools' reading and mathematics achievement results. 
Of the 122 effect sizes, $68(56 \%)$ that were used in this study were negative, which implies that charter school educational programs are producing lower achievement in reading and mathematics. Of the 122 effect sizes, $54(44 \%)$ that were used in this study were positive, indicating charter school educational programs are performing at higher rates than traditional public schools (control group). The analyses also revealed that $6(55 \%)$ of the 11 studies had a mean effect size of 0.5 or greater and that the effects of the moderators on student achievement according to Cohen (1992) were considered large.

Initially, analysis was conducted in an effort to find the mean effect size of mathematics and reading, finding that there was no significant difference between mathematics and reading, $p>.05$. Both subject areas produce essentially the same small to moderate negative impact. Analysis of student level indicated that charter schools are showing a small positive effect on elementary student achievement results, while large negative impacts exist at all other levels. Type of assessment measure used revealed for profit assessments presenting large negative effect on achievement for charter schools. Examination of whether differences exist across geographic region indicate that a large negative impact was revealed for charter schools in the Southern Atlantic region, while large positive impacts were found for the East North Central region. The analysis of socioeconomic status disclosed that charter schools have the greatest positive impact on schools where most students are economically disadvantaged; however, results indicated that charter schools are presenting large negative impacts when they serve students classified as Special Education. Noteworthy is that the trend for the impact of charter school attendance over time is positive and improving. These results suggest that as time moves forward, students at charter schools are performing at a level equivalent to that of students in traditional public school programs. There were no differences found for the moderators of topology, presence of English language learners, or whether or not the charter school had a lottery system in place. Detailed results for the mean effect size measures for each significant moderator and the levels within the moderator are presented in Table 1.

Table 1: Moderators and Level Results

\begin{tabular}{|c|c|c|c|}
\hline Variables and Categories & Number of Effect Size Measures & With-In Groups Effects & Mean Effect Size \\
\hline Mathematics and Reading & & 0.048 & \\
\hline Mathematics & 61 & & $-0.286^{*}$ \\
\hline Reading & 61 & & $-0.254 *$ \\
\hline Student Level & & $184.642 *$ & \\
\hline Elementary School & 78 & & $0.201 *$ \\
\hline Middle School & 12 & & $-1.047 *$ \\
\hline High School & 12 & & $-2.671 *$ \\
\hline Elementary/Middle/High School & 20 & & $-0.183^{*}$ \\
\hline Achievement Measure & & $115.030 *$ & \\
\hline State Assessment & 66 & & $-0.152 *$ \\
\hline District Assessment & 12 & & $-0.295^{*}$ \\
\hline Regional Assessment & 24 & & $0.747 *$ \\
\hline For-Profit Assessment & 20 & & $-1.815 *$ \\
\hline Geographic Region & & $119.121 *$ & \\
\hline Pacific & 10 & & $-0.364 *$ \\
\hline Mountain & 8 & & $-0.427 *$ \\
\hline West South Central & 2 & & -0.080 \\
\hline East North Central & 34 & & $0.524 *$ \\
\hline East South Central & 50 & & $-0.162 *$ \\
\hline Middle Atlantic & 4 & & 0.015 \\
\hline South Atlantic & 14 & & $-2.463^{*}$ \\
\hline Socioeconomic Status & & $59.814 *$ & \\
\hline Less Than $40 \%$ SES & 10 & & $-0.293^{*}$ \\
\hline $50 \%$ to $60 \%$ SES & 12 & & $1.433^{*}$ \\
\hline $80 \%$ to $90 \%$ SES & 12 & & 0.072 \\
\hline Special Education & & $29.463 *$ & \\
\hline Special Education Present & 56 & & $-0.700 *$ \\
\hline Special Education Not Present & 66 & & $0.114 *$ \\
\hline Publication Year & & $112.587 *$ & \\
\hline 2001 & 14 & & $-0.517 *$ \\
\hline 2005 & 12 & & $1.433 *$ \\
\hline
\end{tabular}


Table 1 cont.

\begin{tabular}{lcc}
\hline 2006 & 4 & $-0.474^{*}$ \\
2007 & 34 & $-1.247^{*}$ \\
2008 & 32 & 0.013 \\
2009 & 14 & -0.008 \\
2011 & 12 & 0.072 \\
\hline
\end{tabular}

\section{Publication Bias}

Publication bias is a concern when performing a meta-analysis, and a criticism of the meta-analytic approach (Hunter \& Schmidt, 2004). Publication bias occurs when studies that find significant results for the effect being investigated are more likely to be published than studies that do not find significant findings, therefore making it more likely that these studies will be included in meta-analytic investigations. Publication bias has the potential of inflating the effect size estimates (Hedges, 1986), and therefore it is important that unpublished information be included in performing a meta-analysis. Egger's Test of the Intercept was used to further assess the presence of publication bias. Egger's linear regression method is intended to quantify the publication bias analyses (Egger, Davey, Schneier, \& Minder, 1997). In the Egger test, the standard normal deviation is regressed on precision, defined as the inverse of the standard error. The intercept in this regression corresponds to the slope in a weighted regression of the effect size on the standard error. Power for this test is generally higher than power for the rank correlation method, but is still low unless there is severe bias or a substantial number of effect size measures (Sterne, Gavaghn, \& Egger, 2000). For the current investigation, Egger's test revealed that the intercept was $-0.38209, \mathrm{CI}_{95}$ [$4.50519,3.74101$, with $\mathrm{t}(120)=0.18348, \mathrm{p}=0.85473$. The nonsignificant results indicated that publication bias is not a concern with the current group of research studies.

\section{CONCLUSION}

The current investigation meta-analyzed existing research that directly compared the impact of both charter and public school attendance on students' mathematics and reading achievement results since the inception in YEAR of No Child Left Behind (Hill et al., 2006). The findings of the current investigation suggest that students in charter school programs are not performing at the same level as students in traditional public schools on mathematics or reading achievement exams. Results suggest, however, that the outcomes are more positive for charter schools with elementary-level students, and with students of higher socioeconomic need. Additionally, results suggest that as time progresses, charter school student performance is approaching the level of public school student performance. While this investigation supports the claim that charter schools are moving toward equality with traditional public schools as the No Child Left Behind legislation continues, research suggests that school choice initiatives provide educational opportunities for students both in and out of the traditional public school with the decision left to each family to determine which placement best meets the individual needs of the child.

\section{AUTHOR INFORMATION}

Matthew J. Erickson earned his Ed.D. from Youngstown State University in Educational Leadership and Administration in 2013. He currently serves as an Instructor at Slippery Rock University. Dr. Erickson has conducted various professional development workshops for teachers and paraprofessionals since joining Slippery Rock University in 2011. His teaching focus is in the area of special education, behavior strategies, and assessment. E-mail: matthew.erickson@sru.edu

Karen H. Larwin acquired her Ph.D. from Kent State University in Evaluation, Measurement, and Statistics in 2007. She currently serves as a professor at Youngstown State University. Dr. Larwin has participated as the evaluator on multiple federal and state-wide grant supported projects over the past decade. Her primary teaching focus is in the area of research methods, quantitative methods, evaluation, and measurement. She is currently the Lead Chair for the American Evaluation Association's Quantitative Methods: Theory and Design TIG. E-mail: khlarwin@ysu.edu (Corresponding author) 
Dr. Robert Isherwood is an Associate Professor at Slippery Rock University of Pennsylvania and a partner in the Keystone Educational Consulting Group. Dr. Isherwood has been a professor in the Special Education Department at SRU for nine years. Dr. Isherwood recently co-authored a book titled Strategic Co-teaching in Your School: Using the Co-Design Model. He sits on the editorial boards of the Journal of Ethnographic and Qualitative Research and The Journal of Special Education Apprenticeship. He is also a member of the Advisory Board of the Learning Disabilities Association of America. Dr. Isherwood is a past recipient of the Butler County United Way Red Apple Award for outstanding contribution to the field of education.

\section{REFERENCES}

References marked with an asterisk (*) indicate studies included in the meta-analysis.

1. Akey, T., Plucker, J. A., Hansen, J. A., Michael, R., Branon, S., Fagen, R., \& Zhou, G. (2008). Study of the effectiveness and efficiency of charter schools in Indiana. Bloomington, IN: Center for Evaluation and Education Policy, Indiana University.

2. Ball State University. (2004). Indiana charter schools: Annual report 2003-2004. Muncie, IN: Ball State University, Office of Charter School Research.

3. Barr, J. (2007). Charter school performance in New Jersey. (Unpublished manuscript). Rutgers University, New Brunswick, NJ.

4. *Barr, J., Sadovnik, A., \& Visconti, L. (2006). Charter schools and urban education improvement: A comparison of Newark's district and charter schools. The Urban Review, 38(4), 291-311.

5. Bifulco, R., \& Ladd, H. F. (2004). The impacts of charter schools on student achievement: Evidence from North Carolina. (Unpublished manuscript). University of Connecticut, Storrs, CT.

6. Booker, K., Gill, B, Zimmer, R., \& Sass, T. R. (2007). Achievement and attainment in Chicago charter schools. Santa Monica, CA: Rand.

7. Booker, K., Gilpatric, S. M., Gronberg, T., \& Jansen, D. (2004b). The effect of charter competition on traditional public school students in Texas. (Unpublished manuscript). Texas A\&M University, College Station, TX.

8. Budde, R. (1988). Education by charter: Restructuring school districts. Andover, MA: Regional Laboratory for Educational Improvement of the Northeast and Islands.

9. Buddin, R., \& Zimmer, R. (2005). Student achievement in charter schools: A complex picture. Journal of Policy Analysis and Management, 24(2), 351-371. Retrieved from http://dx.doi.org/10.1002/pam.20093

10. Chau, D., McCaffery, R., Zimmer, G., \& Gill, B. (2003). Student served by charter schools. In R. Zimmer et al., Charter school operations and performance: Evidence from CA (19-36). Santa Monica, CA: RAND.

11. Chen, G. (2007). What is a charter school? Public School Review. Retrieved from http://www.publicschoolreview.com/articles/3

12. Cohen, J. (1992). A power primer. Psychological Bulletin, 112(1), 155-159. Retrieved from http:/web.vu.lt/fsf/d.noreika/files/2011/10/Cohen-J-1992-A-powerprimer-kokia-reika-imtiesdyd\%C5\%BEio.pdf

13. Comey, J. (2008). Performance of students attending District of Columbia Public Schools (DCPS), District of Columbia Public Charter School Board (PCSB) Schools, and District of Columbia Board of Education (BOE) Schools. Washington, DC: Urban Institute.

14. Eberts, R. W., \& Hollenbeck, K. M. (2001). An examination of student achievement in Michigan charter schools. (Unpublished manuscript). W. E. Upjohn Institute for Employment Research.

15. Egger, M., Smith, G. D., Schneider, M., \& Minder, C. (1997). Bias in meta-analysis detected by a simple, graphical test. BMJ, 315, 629-634.

16. Florida Department of Education. (2009). Student achievement in Florida's charter schools: A comparison with achievement in traditional public schools. Tallahassee, FL: Office of Independent Education and Parental Choice.

17. Glass, G. V., McGaw, B., \& Smith, M. L. (1981). Meta-analysis in social research. London, UK: Sage.

18. Greene, J. P., Forster, G., \& Winters, M. A. (2003). Apples to apples: An evaluation of charter schools serving general student populations (Education Working Paper No. 1). New York City, NY: Manhattan Institute, Center for Civic Innovation. 
19. Gronberg, T. J., \& Jansen, D. W. (2005). Texas charter schools: An assessment in 2005. Austin, TX: Texas Public Policy Foundation.

20. Hedges, L. V. (1986). Issues in meta-analysis. In E. Z. Zothkoph (Ed.), Review of Research in Education (pp. 353-398). Washington, DC: American Education Research Association.

21. Hill, P., Angel, L., \& Christensen, J. (2006). Charter school achievement studies. Education, Finance, and Policy, 1(1), 139-140, 144, 150.

22. Horn, J., \& Miron, G. (2000). An evaluation of the Michigan charter school initiative: Performance, accountability, and impact. Kalamazoo, MI: Western Michigan University, The Evaluation Center.

23. Hoxby, C. M. (2004). Achievement in charter schools and regular public schools in the United States: Understanding the differences. Cambridge, MA: Harvard University, National Bureau of Economic Research.

24. Hunter, J. E., \& Schmidt, F. L. (2004). Methods of meta-analysis: Correcting error and bias in research findings. London, UK: Sage.

25. Lacireno-Paquet, N., Holyoke, T., Moser, M., \& Henig, J. (2002). Creaming versus cropping: Charter school enrollment practices in response to market incentives. Educational Evaluation and Policy Analysis, 24(2), 145-158. Retrieved from http://epa.sagepub.com/content/24/2/145.short

26. *McDonald, A. J., Ross, S. M., Bol, L., \& McSparrin-Gallagher, B. (2007). Charter schools as a vehicle for education reform: Implementation and outcomes at three inner-city sites. Journal of Education for Students Placed at Risk, 12(3), 271-300.

27. Miller, R. L. (2003). A study of differences in achievement between Idaho charter schools and their constituent school districts: Exploring and controlling demographics. Unpublished doctoral dissertation, University of Idaho.

28. Miron, G., \& Nelson, C. (2001). Student academic achievement in charter schools: What we know and why we know so little. Columbia University: New York, NY: National Center for the Study of Privatization in Education.

29. Miron, G., Coryn, C., \& Mackety, D. M. (2007). Evaluating the impact of charter schools on student achievement: A longitudinal look at the Great Lake states. East Lansing, MI: The Evaluation Center: The Great Lakes Center for Education Research \&Practice.

30. *Miron, G., Cullen, A., Brooks-Applegate, E., \& Farrell, P. (2007). Evaluation of the Delaware charter school reform: Final report. Kalamazoo, MI: Western Michigan University, The Evaluation Center.

31. Montgomery, B. (2004). Influencing traditional public schools-Working with districts. (Discussion, June 9, 2004). Washington, DC, U.S. Charter School Dialogue.

32. Nathan, J. (1998). Public Schools by Choice: Expanding Opportunities for Parents, Students, and Teachers. Bloomington, IN: Meyer-Stone.

33. National Charter School Research Project, 2005

34. National Charter School Resource Center. (n.d.). Citywide strategies. Retrieved from http://www.charterschoolcenter.org/priority-area/citywide-strategies

35. Ni, Y., \& Arsen, A. (2011). School choice participation rates. Which districts are pressured? Education Policy Analysis Archives, 29(19), 1-26.

36. Noblit, G. W., \& Dickson, C. (2001). North Carolina charter school evaluation report. Raleigh, NC: North Carolina State Board of Education.

37. Office of Program Policy Analysis and Government Accountability. (2005). Charter school performance comparable to other public schools: Stronger accountability needed (Report No. 05-21). Tallahassee, FL: Florida Legislature.

38. Ratterman, M. J., \& Reid, B. (2009). A comparison of student academic growth between Indiana charter schools and traditional public schools. Indianapolis, IN: University of Indianapolis, Center of Excellence in Leadership of Learning.

39. Smith, S. (2001). In J. L. Kincheloe \& S. R. Steinberg (Eds.), The democratic potential of charter schools: Studies in the postmodern theory of education. New York, NY: Peter Lang.

40. Sterne, J. A., Gavaghan, D., \& Egger, M. (2000). Publication and related bias in meta-analysis: Power of statistical tests and prevalence in the literature. J. Clin. Epidemiol., 53 (11), 1119- 1129.

41. Tang, Y. E., \& Betts, J. R. (2006). Student achievement in charter schools in San Diego. (Unpublished manuscript). University of California, San Diego, CA. 
42. Thurman, T. (2010, January 1). Milton Friedman-School choice [Online Forum Comment]. Retrieved from http://blog.heritage.org/2010/01/01/milt-friedman-on-school-choice/

43. Tyack, D. B., \& Cuban, L. (1995). Tinkering toward utopia, A century of public school reform. Cambridge, MA: Harvard University Press.

44. US charter schools: State profiles. (2009). Retrieved 10/12, 2012, from http://www.uscharterschools.org/pub/uscs_docs/ta/steps.htm

45. Vergari, S. (2002). The charter school landscape. Pittsburgh, PA: University of Pittsburgh Press.

46. *Witte, J., Weimer, D., Shober, A., \& Schlomer, P. (2007). The performance of charter schools in Wisconsin. Journal of Policy Analysis and Management, 26(3), 557-573. doi:10.1002/pam.20265.

47. *Woodworth, K. R., David, J. L., Guha, R.,Wang, H., \& Lopez-Torkos, A. (2008). San Francisco Bay area KIPP schools: A study of early implementation and achievement: Final report. Menlo Park, CA: SRI International.

48. Zimmer, R., Buddin, R., Chau, D., Daley, G., Gill, B., Guarino, S., \& Brewer, D. (2003). Charter school operations and performance: Evidence from California. Santa Monica, CA: Rand.

49. *Zimmer, R., Gill, B., Booker, K., Lavertu, S., Sass, T. R., \&Witte, J. (2009). Charter schools in eight states: Effects on achievement, attainment, integration, and competition. Santa Monica, CA: Rand.

50. *Zoblotsky, T. A., Qian, H., Ross, S. M., \& McDonald, A. J. (2008). Analysis of year 4 (2006-07) achievement outcomes for Tennessee elementary charter schools. Memphis, TN: The University of Memphis, Center for Research in Educational Policy. 